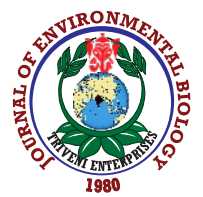

\title{
Seroprevalence of porcine reproductive and respiratory syndrome virus and classical swine fever virus in pigs of Mizoram, India
}

\author{
K. Lalhruaipuii ${ }^{1 *}$, I. Shakuntala ${ }^{1}$ and A. Sen ${ }^{2}$ \\ ${ }^{1}$ ICAR-RC for NEH Region, Mizoram Centre, Kolasib-796 081, India \\ ${ }^{2}$ Animal Health Division, ICAR-RC for NEH Region, Barapani-793001, India \\ *Corresponding Author Email : Ihpuii@gmail.com
}

\section{Abstract}

Aim: This study aimed to evaluate the prevalence of antibodies against two economically significant viral pathogens in domestic pigs like porcine reproductive and respiratory syndrome virus (PRRSV) and classical swine fever virus (CSFV) through a serological study in swine herds in Mizoram, India.

Methodology: Serum samples were collected from apparently healthy and suspected pigs of different age groups comprising weaners, growers and adult in four districts (Aizawl, Champhai, Kolasib and Serchhip) of Mizoram during February, 2018 to June, 2019. Seroprevalence of CSFV and PRRSV specific antibodies was detected by enzyme-linked immunosorbentassay (ELISA).

Results: Out of 420 samples, 117 samples were found positive for PRRSV, 171 samples for CSFV indicating a mean positivity of $27.86 \%$ and $40.48 \%$. Presence of mixed infection was observed in $13.33 \%$ samples.

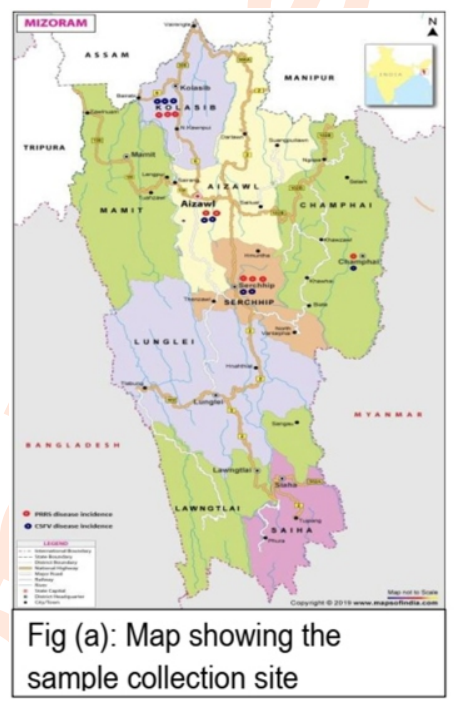

Interpretation: The present study demonstrated the extensive circulation of classical swine fever virus and porcine reproductive and respiratory syndrome virus among domestic pig populations of Mizoram, India.

Key words: Antibodies, CSF virus, ELISA, Pigs, PRRS virus, Serological study

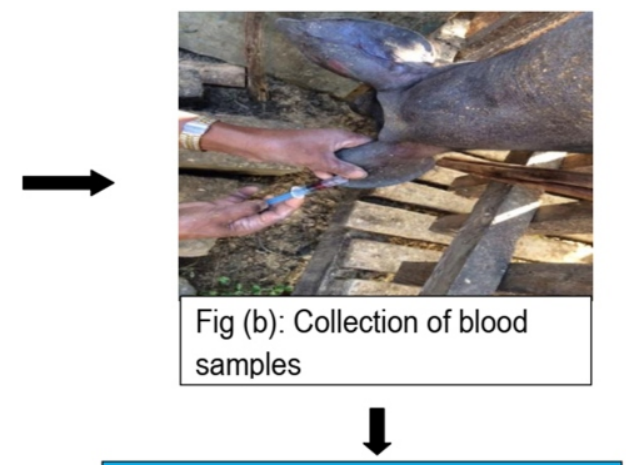

420 serum samples were collected from apparently healthy and suspected pigs of different age groups from four districts (Aizawl, Champhai, Kolasib and Serchhip) of Mizoram

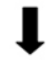

The overall prevalence of PRRSV and CSFV antibodies detected in the study period was $27.86 \%$ and $40.71 \%$ from four districts of Mizoram
All serum samples were tested for PRRSV and CSFV-specific antibodies using a commercially available enzyme - linked immunosorbent assays (ELISA) kit according to the manufacturer's instruction

How to cite : Lalhruaipuii, K., I. Shakuntala and A. Sen: Seroprevalence of porcine reproductive and respiratory syndrome virus and classical swine fever virus in pigs of Mizoram, India. J. Environ. Biol., 41, 915-920 (2020). 


\section{Introduction}

Porcine reproductive and respiratory syndrome (PRRS) is a highly infectious viral disease of swine. It was first recognized in 1987 in the United States of America and is characterized by reproductive failure in sows and respiratory tract illness in pigs (Keffaber, 1989; Albina, 1997; Pejsak et al., 1997; Rossow, 1998). PRRSV belongs to Arteriviridae family in the order of Nidovirales within the genus Arterivirus, which is an enveloped virus with a linear positive-stranded RNA genome with an approximate diameter of 50-65 nm (Wensvoort et al., 1991; Collins et al., 1992). The virus causes abortions in late pregnancy, stillborn or weak piglets, reproductive failure, respiratory disease and high death rates in suckling, and weaned pigs (Zimmerman et al., 2012). It became pandemic, covering North America, Europe and Asia in the subsequent years (Morin et al., 1991; Wensvoort et al., 1991; Baron et al., 1992; Benfield et al., 1992; Bøtner et al., 1994; Kuwahara et al., 1994). Presently, the disease occurred in most pig-producing countries and caused enormous economic loss to the swine industry (Thanapongtharm etal., 2014; Scanlan etal., 2019).

India has reported the first outbreak of PRRS in the pig population of Mizoram state to the Office International des Epizooties (OIE) on 26 June 2013. Since its first outbreak in 2013, PRRS had been established as an enzootic disease in pig population of Mizoram and caused huge loss to the pig farmers (Rajkhowa et al., 2016). The disease was observed to affect all age groups including the pregnant sows with morbidity rate 44.01\%-80.29\% and mortality rate 14.51\%-66.11\% (Gogoi et al., 2017). Classical swine fever virus (CSFV), also known as 'hog cholera', is a highly contagious and often fatal disease of domestic pigs and wild boar (Leifer et al., 2010) economically affecting various parts of the world (Edwards et al., 2000). Classical swine fever, classified under list-A diseases by Office International des Epizooties, is considered as a transboundary animal disease by Food and Agriculture Organization (Sarma et al., 2008). It causes significant economic losses to the swine industry throughout the world. The disease is currently endemic to India especially in intensive pig rearing units of north-eastern, northern and southern states of India (Saini et al., 2000; Sarma et al., 2011; Malsawmkima et al., 2015).

In the north-eastern region, the outbreaks of classical swine fever virus have been reported from Nagaland, Mizoram, Meghalaya and Assam (Rahman et al., 2001; Sarma et al., 2011; Rajkhowa et al., 2013; Malsawmkima et al., 2015; Mukherjee et al., 2018; Barman et al., 2020). The Department of Veterinary and Animal Husbandry, Government of Mizoram, has identified the CSF as disease of special economic importance for Mizoram in their Annual Report (2002-2003). The disease is characterized as a hemorrhagic fever in its acute form leading to chronic and clinically inapparent form (Edwards et al., 2000; Moennig, 2000). The causative agent 'CSF virus' (CSFV) belongs to family Flaviviridae, a member of genus Pestivirus, is a small, enveloped virus with a non segmented, single-stranded positive RNA genome (Gong et al., 2016).
In North-eastern India, especially Mizoram, the majority of livestock farmers are dependent on healthy pig population for their livelihood. The swine population plays a major role for the socio-economic status of the state of Mizoram. According to 19th Quinquennial Livestock Census of India (2012) data reproduced in the Mizoram Economic Survey 2017-18, total population of Livestock in Mizoram is 3,84,604 where pigs constitute the largest group $(69.33 \%)$, followed by cattle $(9.95 \%)$, goat $(5.7 \%)$. Porcine reproductive and respiratory syndrome virus and classical swine fever virus are economically important swine viruses causing reproductive failure/respiratory symptoms in pigs (Liu et al., 2013; Chen et al., 2019). It stands clear that the health of pig population should be given high priority, and diagnosis of such economically important diseases like reproductive problems becomes crucial for sustaining pig production. In view of the above, this study was conducted to determine the antibody prevalence of PRRSV and CSFV infection in pigs raised in different districts of Mizoram.

\section{Materials and Methods}

Ethical approval: As per Committee for the Purpose of Control and Supervision of Experiments on Animal Guidelines, a study involving clinical samples does not require the approval of Institute Animal Ethics Committee. However, the samples collected for the present study followed standard sample collection methods without causing any harm or stress to the animals (Parasuraman et al., 2010).

Study area and data collection: In all 420 serum samples were collected from apparently healthy and suspected pigs of different age groups comprising weaners, growers and adult from organized and unorganized farms from four districts (Aizawl, Champhai, Kolasib and Serchhip) of Mizoram, India during February, 2018 to June, 2019. These districts were selected due to its close proximity to the border of Myanmar where Mizoram shares a porous international border of $510 \mathrm{~km}$ with Myanmar. There are chances of growing risk for animal populations to become exposed to transboundary animal disease pathogens.

Sample collection: Approximately, 4-5 ml of blood was collected from intra-cardiac in piglets and ear vein in older pigs. Blood samples were collected in sterile vacutainer tubes without ethylenediaminetetraacetic acid (EDTA) and centrifuged at 1000 rpm for $3 \mathrm{~min}$. Serum was separated and stored at $-20^{\circ} \mathrm{C}$ before examination.

Serology: All serum samples collected from apparently healthy and suspected pigs of different age groups were tested for PRRSV-specific antibodies using a commercially available enzyme-linked immunosorbent assays (ELISA) kit.

Serum samples were considered positive for PRRSV antibody if the optical density value of the sample to that of positive control was $\geq 0.4$ according to the manufacturer's instruction. Similarly, for detection of CSFV-specific antibodies commercially available ELISA kit was used following 
manufacturer's instructions. The results obtained were expressed as positive and negative based on the manufacturer's recommended cutoff value (Table 1).

\section{Results and Discussion}

Serum samples were collected randomly from organized and unorganized farms of four districts of Mizoram, India bordering Myanmar since majority of the pigs were imported through the international border illegally, not only for slaughtering but also for breeding purpose. Antibodies to PRRSV and CSFV were detected in pig population in these four districts (Aizawl, Champhai, Serchhip and Kolasib) from February, 2018 to June, 2019. The overall prevalence of PRRSV antibodies detected in the study period was $27.86 \%$ in Table 2 which was comparatively less compared to earlier reports where $61.96 \%$ PRRSV seroprevalence was reported in Aizawl district, Mizoram during the outbreak period from March to June, 2013 (Rajkhowa et al., 2016). Previous studies have reported a prevalence of $18.5 \%$, $17.2 \%, 3.62 \%$ and $0.84 \%$ PRRSV antibody sero-positive samples in pigs from Nepal, Vietnam and North East, India (Mahesh et al., 2015; Pegu et al., 2017; Mukherjee et al., 2018; Lee et al., 2020) which is relatively lesser than the present study.

This difference may be due to the geographical location, time of sample collection, test procedures, sample size etc. The present finding corroborates the reports of Gogoi et al. (2017) who revealed $28.26 \%$ seropositivity. The report on systematic studies on PRRSV has not been reported from India, although genomic and phylogenetic studies are available (Rajkhowa et al., 2015, 2016). Interestingly, animals with positive PRRSV antibody have been also found positive for CSFV antibody, i.e., 13.33\% serum samples showed the presence of PRRSV and CSFV. The presence of PRRSV can also have profound effect on the vaccination efficiency because PRRSV is immunesuppressive and it seriously inhibits the immune response to CSF vaccine (Tao et al., 2013; Mao et al., 2015; Zhou, 2019). During the study period, Kolasib districts of Mizoram showed the highest prevalence (34.69\%) of PRRSV antibodies as compared to other three districts of Mizoram, i.e., Aizawl (25.00\%), Champhai (17.9\%) and Serchhip (34.5\%) as shown in Fig. 1. In the first outbreak of PRRSV in Mizoram on June, 2013 (Rajkhowa et al., 2015) no PRRSV positive samples were detected from Kolasib districts of Mizoram. This study showed an extensive circulation

Table 1: ELISA kit used for the detection of specific antibody with cutoff value

\begin{tabular}{lll}
\hline Agent $^{\mathrm{a}}$ & ELISA test $^{\mathrm{b}}$ & Positive threshold $^{\mathrm{c}}$ \\
\hline CSFV & HERDCHEK CSFV Ab (IDEXX) & Blocking $\% \geq 40 \%$ \\
PRRSV & HERDCHEK PRRS 3X Ab (IDEXX) & OD $\geq 0.4$
\end{tabular}

${ }^{\mathrm{a}} \mathrm{CSFV}=$ Classical swine fever virus2, PRRSV=Porcine reproductive and

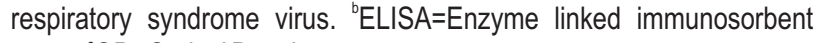
assay. ${ }^{\circ} \mathrm{OD}=0$ ptical Density of PRRSV as vaccination against this disease is not practiced in Mizoram and, hence, possibility of antibody production through vaccination is completely ruled out. There was high prevalence of PRRSV in more than 6 month-old pigs (38.1\%) as compared to pigs less than 6 months (13.6\%) (Fig. 2). Similarly, 29.7\% female serum samples showed higher prevalence to PRRSV as compared to males (25.9\%).

This finding is in corroboration with the results of Mahesh et al. (2015) who reported high prevalence of PRRSV in more than 6 month-old pigs than pigs less than 6 month of age and also higher prevalence of PRRSV in female serum as compared to males. In this study, the overall prevalence of CSFV antibodies detected was $40.71 \%$ (Table 2) which was comparatively less when compared to previous pan India surveillance finding of 594 serum samples from 12 states and 287 tissue samples tested from 13 states of India using commercial ELISA kits in which mean prevalence of CSFV antibodies in suspected sera was $63.3 \%$ and CSFV antigen in the suspected samples was $76.7 \%$ (Nandi et al., 2011). The present study is in corroboration with the earlier study where $45.15 \%$ seroprevalence was detected (Mukherjee et al., 2018) but higher than reported by earlier worker, i.e., 37\% (Patil et al., 2018). The study revealed the endemicity of the diseases in Mizoram since majority of the samples were collected from apparently healthy and suspected animals. Unrestricted movement of pigs from one region to another within the country and across the porous international border surrounding the North Eastern States, unavailability of adequate doses of vaccine and poor public awareness are some of the important factors that might have helped in perpetuating the disease in the state (Malsawmkima et al., 2015).

Detection of virus-specific antibody in animals indicates an indirect evidence of virus persistence in the farms. This implies that swine population acts as a major carrier of viruses and thus plays an important role in its dissemination. Harboring these viral pathogens without showing any distinguishable symptoms, these animals may be considered as reservoir host as viremia is prolonged and most infections are subclinical (Mukherjee et al., 2018). In the present study, Kolasib districts of Mizoram has shown the highest prevalence (54.1\%) of CSFV antibodies compared to Aizawl (45\%), Champhai (23.2\%) and Serchhip $(42.7 \%)$ districts as shown in Fig. 1. High seroprevalence of CSFV could be due to lack of awareness about vaccination

Table 2: District-wise details of positive serum samples by ELISA

\begin{tabular}{llll}
\hline District & \multirow{2}{*}{ No. of samples } & \multicolumn{2}{c}{ Viral diseases } \\
\cline { 3 - 4 } & & PRRSV & CSFV \\
\hline Aizawl & 100 & $25(25.00)$ & $45(45.00)$ \\
Champhai & 112 & $20(17.85)$ & $26(23.21)$ \\
Serchhip & 110 & $38(34.54)$ & $47(42.73)$ \\
Kolasib & 98 & $34(34.69)$ & $53(54.08)$ \\
Total: & 420 & $117(27.86)$ & $171(40.71)$ \\
\hline
\end{tabular}

${ }^{*}$ Figures in parenthesis indicates percentage 


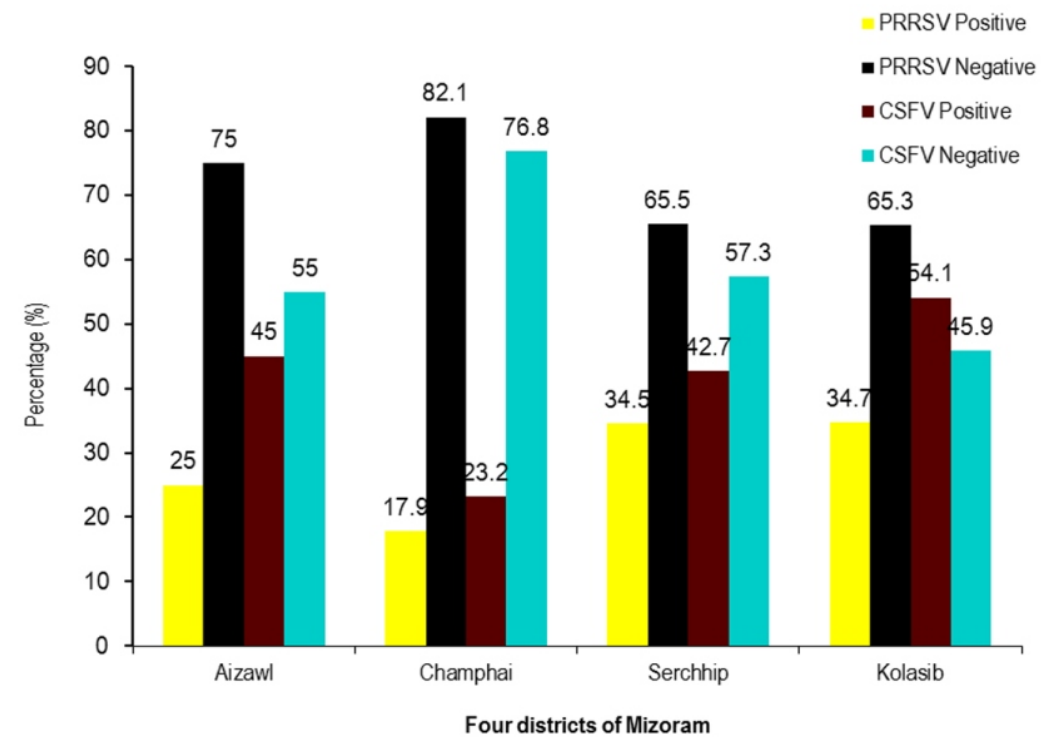

Fig. 1: Seroprevalence of PRRSV and CSFV in four districts of Mizoram.

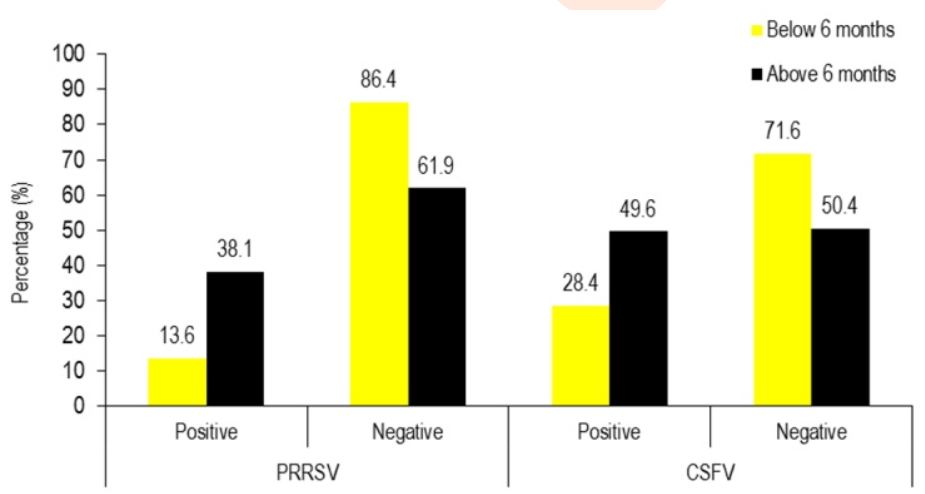

Age wise disease incidence

Fig. 2: Age wise seroprevalence of PRRSV and CSFV in Mizoram.

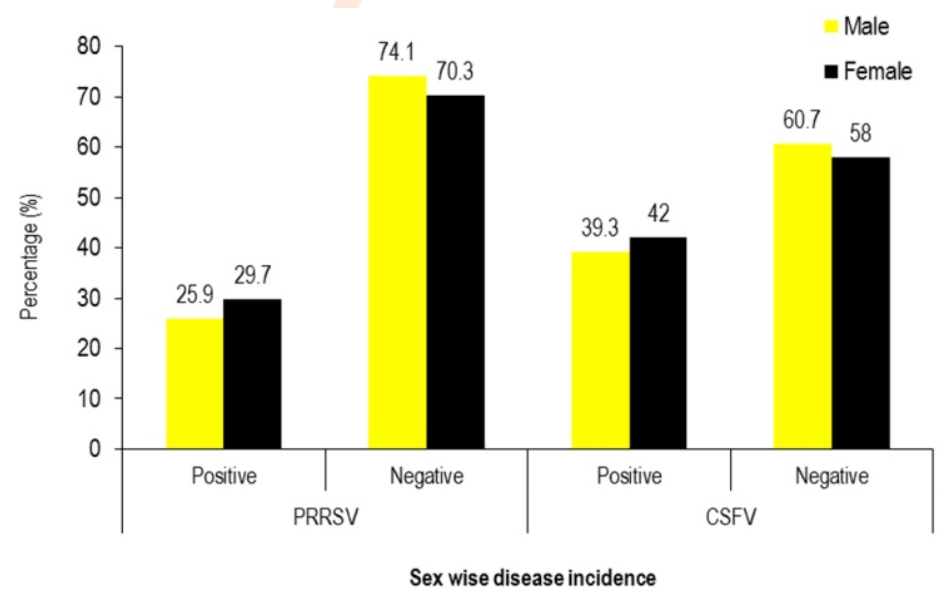

Fig. 3: Sex wise seroprevalence of PRRSV and CSFV in Mizoram. 
programme of CSFV in unorganized farms or due to inappropriate titer of vaccine, cold chain abuse, and inappropriate vaccine dose leading to vaccination failure (Nandi et al., 2011; Mukherjee et al., 2018). There was high prevalence of CSFV in more than 6 months old pigs ( $38.1 \%$ ) as compared to pigs less than 6 months old ( 28.4 $\%$ ). Similarly, $60.7 \%$ male serum samples showed higher prevalence to CSFV as compared to females $(58 \%)$ in Fig. 3. It could be due to higher sample size in more than 6 months compared to less than 6 months old pigs. The study revealed an alarmingly high prevalence of PRRSV and CSFV antibody among different age group of pigs from organized and unorganized farms of different districts of Mizoram which is retarding the growth of swine industry in the state. To the author's best knowledge, this is the first observation on the seroprevalence of CSFV and PRRSV from different districts of pig population in Mizoram, India. This baseline data will be useful for formulation of control and eradication programmes.

\section{Acknowledgment}

The authors are grateful to the Director, ICAR-RC for NEH Region, Umiam, Barapani Animal Health, ICAR, for funding this study and providing the necessary facilities to conduct the presentwork.

\section{References}

Albina, E.: Epidemiology of porcine reproductive and respiratory syndrome (PRRS): An overview. Vet. Microbiol., 55, 309-16 (1997).

Barman, N.N., S.S. Patil, R. Kurli, P. Deka, D.P. Bora, G. Deka, K.M. Ranjitha, C. Shivaranjini, P. Roy and K.P. Suresh: Meta-analysis of the prevalence of livestock diseases in North Eastern Region of India. Vet. World, 13, 80-91 (2020).

Baron, T., E. Albina, Y. Leforban, F. Madec, H. Guilmoto, J. PlanaDuran and P. Vannier: Report on the first outbreaks of the porcine reproductive and respiratory syndrome (PRRS) in France. Diagnosis and viral isolation. Ann. Rech. Vet., 23, 161-166 (1992).

Benfield, D.A., E. Nelson, J.E. Collins, L. Harris, S.M. Goya, D. Robison, W.T. Christianson, R.B. Morrison, D.E. Gorcyca and D.W. Chladek: Characterization of swine infertility and respiratory syndrome (SIRS) virus (isolate ATCC-VR2332). J. Vet. Diagn. Invest., 4, 127-133 (1992).

Bøtner, A., J. Nielsen and V. Bille-Hansen: Isolation of porcine reproductive and respiratory syndrome (PRRS) virus in a Danish swine herd and experimental infection of pregnant gilts with the virus. Vet. Microbiol., 40, 351-360 (1994).

Chen, J., H. Wang, J. Bai, W. Liu, X. Liu, D. Yu, T. Feng, Z. Sun, L. Zhang, L. Ma, Y. Hu, Y. Zou, T. Tan, J. Zhong, M. Hu, X. Bai, D. Pan, Y. Xing, Y. Zhao, K. Tian, X. Hu and N. Li: Generartion of pigs resistant to highly pathogenic-porcine reproductive and respiratory syndrome virus through gene editing of CD163. Int. J. Biol. Sci., 15, 481-492 (2019).

Collins, J.E., D.A. Benfield, W.T. Christianson, L. Harris, J.C. Hennings, D.P. Shaw, S.M. Goyal, S. McCullough, R.B. Morrison, H.S. Joo, D. Gorcyca and D. Chladek: Isolation of swine infertility and respiratory syndrome virus (isolate ATCC VR-2332) in North America and experimental reproduction of the disease in gnotobiotic pigs. J. Vet. Diagn. Invest., 4, 117-126 (1992).

Edwards, S., A. Fukusho, P. Lefevre, A. Lipowski, Z. Pejsak, P. Roehe and J. Westergaard: Classical swine fever: The global situation. Vet. Microbiol., 73, 103-119 (2000).

Gogoi, A., T.K. Rajkhowa, Y.D. Singh, R. Ravindran, R.S. Arya and L. Hauhnar: Epidemiology of porcine reproductive and respiratory syndrome (PRRS) outbreak in India. Indian J. Vet. Pathol., 41, 31 37 (2017).

Gong, W., J. Wu, Z. Lu, L. Zhang, S. Qin, F. Chen, Z. Peng, Q. Wang, L. Ma, A. Bai, H. Guo, J. Shi and C. Tu: Genetic diversity of subgenotype 2.1 isolates of classical swine fever virus. Infect. Genet. Evol., 41, 218-226 (2016).

Keffaber, K.: Reproductive failure of unknown etiology. Am. Assoc. Swine Pract. Newsl., 1, 1-10 (1989).

Kuwahara, H., T. Nunoya, M. Tajima, A. Kato and T. Samejima: An outbreak of porcine reproductive and respiratory syndrome in Japan. J. Vet. Med. Sci., 56, 901-909 (1994).

Lee, H.S., V.N. Bui, H.X. Nguyen, A.N. Bui, T.D. Hoang, H.N. Viet, D.G Randolph and B. Wieland: Seroprevalence of multi-pathogen and description of farm movement in pigs in two provinces in Vietnam. BMC Vet. Res., 16, Article Number, 15 (2020).

Leifer, I., B. Hoffmann, D. Hoper, T.B. Rasmuseen, S. Blome, G. Strebelow, D. Horeth-Bontgen, C. Staubach and M. Beer: Molecular epidemiology of current classical swine fever virus isolates of wild boar in Germany. J. Gen. Virol., 91, 2687-2697 (2010).

Liu, J.K., C.H. Wei, X.Y. Yang, A.L. Dai and X.H. Li: Multiplex PCR for the simultaneous detection of porcine reproductive and respiratory syndrome virus, classical swine fever virus, and porcine circovirus in pigs. Mol. Cell. Probes, 27, 149-152 (2013).

Mahesh, K.C., B.R. Joshi, S.P. Shrestha, M. Prajapati, D. Kathayat and S. Dhakal: Sero-prevalence of porcine reproductive and respiratory syndrome (PRRS) in pigs of different developmental regions of Nepal. Int. J. Appl. Sci. Biotechnol., 3, 218-222 (2015).

Malsawmkima, D., T.K. Rajkhowa, R. Chandra and T.K. Dutta: Pathology and molecular diagnosis of classical swine fever in Mizoram. Vet. World, 8, 76-81 (2015).

Mao, L., W. Li, X. Liu, F. Hao, L. Yang, J. Deng, W. Zhang, J. Wei and J. Jiang: Chinese border disease virus strain JSLS12-01 infects piglets and down-regulates the antibody responses of classical swine fever virus C strain vaccination. Vaccine, 33, 3918-22 (2015).

Moennig, V.: Introduction to classical swine fever: Virus, disease and control policy. Vet. Microbiol., 73, 93-102 (2000).

Morin, M., Y. Elazhary and C. Girard: Porcine reproductive and respiratory syndrome in Québec. Vet Rec., 129 (1991). doi:10.1136/vr.129.11.252-b. PMID: 1659760

Mukherjee, P., A. Karam, U. Singh, A.K. Chakraborty, S. Huidrom, A. Sen and I. Sharma: Seroprevalence of selected viral pathogens in pigs reared in organized farms of Meghalaya from 2014 to 16. Vet. World, 11, 42-47 (2018).

Nandi, S., D. Muthuchelvan, A. Ahuja, S. Bisht, V. Chander, A.B. Pandey and R.K. Singh: Prevalence of classical Swine fever virus in India: A 6-year study (2004-2010). Transbound. Emerg. Dis., 58, 461$463(2011)$.

Parasuraman, S., R. Raveendran and R. Kesavan: Blood sample collection in small laboratory animals. J. Pharmacol. Pharmacother., 1, 87-93 (2010)

Patil, S.S., K.P. Suresh, S. Saha, A. Prajapati, D. Hemadri and P. Roy: Meta-analysis of classical swine fever prevalence in pigs in India: $A$ 5-year study. Vet. World, 11, 297-303 (2018)

Pegu, S.R., D.K. Sarma, S. Rajkhowa and M. Choudhury: Seroprevelance and pathology of important viral pathogens causing reproductive problems in domestic pigs of NE India. J. Entomol. Zool. Stud., 5, 1816-1818(2017). 
Pejsak, Z., T. Stadejek and I. Markowska-Daniel: Clinical signs and economic losses caused by porcine reproductive and respiratory syndrome virus in a large breeding farm. Vet. Microbiol., 55, 317-322 (1997).

Rahman, T., D.K. Sarma, G.K. Baruah, A. Chakraborty, D.C. Pathak, S. Goswami and S.M. Tamuli: Pathology of a typical form of swine fever. Indian J. Vet. Pathol., 25, 5-7 (2001).

Rajkhowa, T.K., L. Hauhnar and Jamlianthang: Studies on clinicopathology and diagnosis of CSF in Zovawk pigs: An indigenous pig of Mizoram, India. Indian J. Anim. Sci., 83, 620-624 (2013).

Rajkhowa, T.K., G.J. Mohanarao, A. Gogoi and L. Hauhnar: Indian porcine reproductive and respiratory syndrome virus bears discontinuous deletion of 30 amino acids in nonstructural protein 2. Virus Dis., 27, 287-293 (2016).

Rajkhowa, T.K., G.J. Mohanarao, A. Gogoi, L. Hauhnar and L. Isaac: Porcine reproductive and respiratory syndrome virus (PRRSV) from the first outbreak of Indiashows close relationship with the highly pathogenic variant of China. Vet. Quart., 35, 186-193 (2015).

Rossow, K.D.: Porcine reproductive and respiratory syndrome. Vet. Pathol., 35, 1-20 (1998).

Saini, S.S., N.K. Dhand, D.R. Sharma and S.K. Sood: An outbreak of swine fever in Punjab. Indian J. Vet. Pathol., 24, 135-135 (2000).

Sarma, D.K., L. Krishna and J. Mishri: Classical swine fever in pigs and its status in India: Areview. Indian J. Anim. Sci., 78, 1311-1317 (2008).

Sarma, D.K., N. Mishra, S. Vilcek, K. Rajukumar, S.P. Behera, R.K.
Nema, P. Dubey and S.C. Dubey: Phylogenetic analysis of recent classical swine fever virus (CSFV) isolates from Assam, India. Comp. Immunol. Microbiol. Infect. Dis., 34, 11-15 (2011).

Scanlan, C.L., A. M. Putz, K. A. Gray and N.V.L. Serao: Genetic analysis of reproductive performance in sows during porcine reproductive and respiratory syndrome (PRRS) and porcine epidemic diarrhea (PED) outbreaks. J. Anim. Sci. Biotech., 10, Article Number, 22 (2019).

Tao, J., J. Liao, Y. Wang, X. Zhang, J. Wang and G. Zhu: Bovine viral diarrhea virus (BVDV) infections in pigs. Vet. Microbiol., 165, 185189 (2013).

Thanapongtharm, W., C. Linard, N. Pamaranon, S. Kawkalong, T. Noimoh, K. Chanachai, T. Parakgamawongsa and M. Gilbert: Spatial epidemiology of porcine reproductive and respiratory syndrome in Thailand. BMC Vet. Res., 10, 174 (2014). doi:10.1186 /s12917-014-0174-y

Wensvoort, G., C. Terpstra, J.M. Pol, E.A. TerLaak, M. Bloemraad, E.P. de Kluyver, C. Kragten, L. van Buiten, A. den Besten and F. Wagenaar: Mystery swine disease in The Netherlands: The isolation of Lelystad virus. Vet. Q., 13, 121-130 (1991).

Zhou, B.: Classical swine fever in China- An update Minireview. Front. Vet. Sci., 6, 187 (2019). DOI: 10.3389/fvets.2019.00187

Zimmerman, J.J., D.A. Benfield, S.A. Dee, M.P. Murtaugh, T. Stadejek, G.W. Stevenson and M. Torremorell: Diseases of swine: Porcine reproductive and respira-tory syndrome virus (porcine arteri virus). Dis. Swine, 10, 461-486 (2012). 